\title{
Menurunnya Penutur Bahasa Indonesia Sebagai Lingua Franca
}

\author{
Tato Nuryanto
}

\begin{abstract}
Abstrak
Penggunaan bahasa asing secara tidak proporsional, menurun dan berkurangnya penutur bahasa Indonesia, serta semakin ditinggalkannya bahasa daerah, termasuk ada usaha pengambilan aset budaya kita oleh beberapa negara tetangga menjadi fakta bahwa bangsa ini sedang mengalami krisis jati diri sebagai suatu bangsa. Hal ini bisa jadi karena ketidaktahuan kita terhadap kedudukan dan fungsi bahasa dalam kehidupan berbangsa dan bernegara, serta kualitas hidup yang rendah. Sebenarnya bahasa Indonesia memiliki kedudukan dan fungsi yang sangat penting, seperti yang tercantum pada ikrar Sumpah Pemuda tahun 1928 yang berbunyi Kami putra dan putri Indonesia menjunjung bahasa persatuan, bahasa Indonesia. Ini berarti bahwa bahasa Indonesia berkedudukan sebagai bahasa Nasional; kedudukannya berada di atas bahasa-bahasa daerah. Selain itu, di dalam Undang-Undang Dasar 1945 tercantum pasal khusus (Bab XV, Pasal 36) mengenai kedudukan bahasa Indonesia yang menyatakan bahwa bahasa Negara adalah bahasa Indonesia. Disadari atau tidak, generasi muda dan masyarakat masih banyak yang belum tahu tentang kedudukan dan fungsi bahasa Indonesia tersebut. Mereka lupa bahwa bahasa Indonesia sebenarnya memiliki fungsi sebagai lambang kebanggaan kebangsaan, identitas nasional, alat perhubungan atarwarga, antardaerah, dan antarbudaya, dan alat yang memungkinkan penyatuan berbagai suku bangsa dengan latar belakang sosial budaya dan bahasanya masing-masing ke dalam kesatuan kebangsaan Indonesia. Sudah sangat jelas bahwa bahasa Indonesia sebagai bahasa perantara pergaulan (lingua franca) dari zaman dahulu kala.
\end{abstract}

Kata Kunci : Penutur, bahasa Indonesia, Lingua Franca

\section{A. Pendahuluan}

Jika kita ingin membicarakan perkembangan bahasa Indonesia, mau tidak mau harus membicarakan bahasa Melayu sebagai sumber atau akar bahasa Indonesia yang sampai saat ini kita pergunakan. Bahasa Indonesia tumbuh dan berkembang dari bahasa Melayu, yang sejak dahulu sudah dipakai sebagai 
bahasa perantara (lingua franca), bukan saja di Kepulauan Nusantara, melainkan juga hampir diseluruh Asia Tenggara.

Banyak pertanyaan yang sering muncul yaitu kapan sebenarnya bahasa Melayu mulai dipergunakan sebagai alat komunikasi. Berbagai batu bertulis (prasasti) kuno yang ditemukan, seperti (1) Prasasti Kedukan Bukit di Palembang, tahun 683, (2) Prasasti Talang Tuo di Palembang, tahun 684, (3) Prasasti Kota Kapur di Bangka Barat, tahun 686, dan (4) Prasasti Karang Brahi, Bangko, Kabupaten Merangin, Jambi, tahun 688, yang bertulis Pra-Nagari dan bahasanya bahasa Melayu Kuno, memberi petunjuk kepada kita bahwa bahasa Melayu dalam bentuk bahasa Melayu Kuno sudah dipakai sebagai alat komunikasi pada zaman Sriwijaya (Halim, 1979: 6-7). Prasasti-prasasti yang juga tertulis di dalam bahasa Melayu Kuno terdapat di Jawa Tengah (Prasasti Gandasuli, tahun 832) dan di Bogor (Prasasti Bogor, tahun 942). Kedua prasasti di Pulau Jawa itu memperkuat pula dugaan kita bahwa bahasa Melayu Kuno pada waktu itu tidak saja dipakai di Pulau Sumatra, tetapi juga dipakai di Pulau Jawa.

Untuk memperkuat pernyataan tersebut di atas, berikut ini dikutipkan sebagian bunyi batu bertulis (Prasasti) Kedukan Bukit.

Swastie syrie syaka warsaatieta 605 ekadasyii syuklapaksa wulan waisyaakha dapunta hyang naayik di saamwan mangalap siddhayaatra di saptamie syuklapaksa wulan jyestha dapunta hyang marlapas dari minanga taamwan ...

(Selamat! Pada tahun syaka 605 hari kesebelas pada masa terang bulan Waisyaakha, tuan kita yang mulia naik di perahu menjemput siddhayaatra. Pada hari ketujuh, pada masa terang bulan Jyestha, tuan kita yang mulia berlepas dari Minanga Taamwan ...)

Kalau kita perhatikan dengan saksama, ternyata prasasti ini memiliki katakata (dicetak dengan huruf miring) yang masih kita kenal sekarang walaupun waktu sudah lebih dari 1.400 tahun. 
Berdasarkan petunjuk-petunjuk lainnya, dapatlah kita kemukakan bahwa pada zaman Sriwijaya bahasa Melayu berfungsi sebagai berikut.

1. Bahasa Melayu berfungsi sebagai bahasa kebudayaan, yaitu bahasa buku-buku yang berisi aturan-aturan hidup dan sastra.

2. Bahasa Melayu berfungsi sebagai bahasa perhubungan (lingua franca) antarsuku di Indonesia.

3. Bah asa Melayu berfungsi sebagai bahasa perdagangan, terutama di sepanjang pantai, baik bagi suku yang ada di Indonesia maupun bagi pedagang-pedagang yang dating dari luar Indonesia.

4. Bahasa Melayu berfungsi sebagai bahasa resmi kerajaan.

Pada tanggal 28 Oktober 1928, para pemuda kita mengikrarkan Sumpah Pemuda. Naskah Putusan Kongres Pemuda Indonesia Tahun 1928 itu berisi tiga butir kebulatan tekad sebagai berikut.

Pertama : Kami putra dan putri Indonesia mengaku bertumpah darah yang satu, tanah Indonesia.

Kedua : Kami putra dan putri Indonesia mengaku berbangsa yang satu, bangsa Indonesia.

Ketiga : Kami putra dan putri Indonesia menjunjung bahasa Persatuan, bahasa Indonesia.

Pernyataan yang pertama adalah pengakuan bahwa pulau-pulau yang bertebaran dan lautan yang menghubungkan pulau-pulau yang merupakan wilayah Republik Indonesia sekarang adalah satu kesatuan tumpah darah (tempat kelahiran) yang disebut Tanah Air Indonesia. Pernyataan yang kedua adalah pengakuan bahwa manusia-manusia yang menempati bumi Indonesia itu juga merupakan satu kesatuan yang disebut bangsa Indonesia. Pernyataan yang ketiga tidak merupakan pengakuan "berbahasa satu", tetapi merupakan pernyataan tekad kebahasaan yang menyatakan bahwa kita, bangsa Indonesia, menjunjung tinggi bahasa persatuan, yaitu bahasa Indonesia (Halim, 1983: 2-3). Dengan diikrarkannya Sumpah Pemuda, resmilah bahasa Melayu, yang sudah dipakai 
sejak pertengahan Abad VII itu, menjadi bahasa Indonesia.Bahasa Indonesia secara perlahan-lahan, tetapi pasti, berkembang dan tumbuh terus. Akhir-akhir ini perkembangannya itu menjadi demikian pesatnya sehingga bahasa itu menjelma menjadi bahasa modern, yang kaya akan kosa kata dan mantap dalam struktur.

\section{B. Pembahasan}

\section{Kedudukan Bahasa Indonesia}

Bisa jadi kita belum banyak yang tahu bahwa bahasa Indonesia memiliki dua kedudukan penting, yakni sebagai Bahasa Nasional dan Bahasa Negara. Dalam kedudukannya sebagai Bahasa Nasional yang sumber hukumnya adalah Sumpah Pemuda, 28 Oktober 1928, bahasa Indonesia memiliki fungsi sebagai (1) lambang kebanggaan kebangsaan, (2) lambang identitas nasional, (3) alat perhubungan antarwarga,antardaerah, dan antarbudaya, dan (4) alat yang memungkinkan penyatuan berbagai suku bangsa dengan latar belakang sosial budaya dan bahasanya masing-masing kedalam kesatuan kebangsaan Indonesia.

Begitu juga dalam kedudukannya sebagai Bahasa Negara yang dasar hukumnya adalah UUD 1945, Bab XV, Pasal 36 menyatakan bahwa bahasa negara adalah bahasa Indonesia. Memiliki fungsi sebagai (1) bahasa resmi kenegaraan, (2) bahasa pengantar di dalam dunia pendidikan, (3) alat perhubungan pada tingkat nasional untuk kepentingan perencanaan dan pelaksanaan pembangunan, dan (4) alat pengembangan kebudayaan, ilmu pengetahuan dan teknologi.

Mari kita coba telusuri lebih jauh tentang kedudukan dan fungsi bahasa Indonesia yang sejak dulu sudah dipakai sebagai bahasa perantara (lingua franca). Sebagai lambang kebanggaan kebangsaan, bahasa Indonesia mencerminkan nilai-nilai sosial budaya yang mendasari rasa kebangsaan kita. 
Atas dasar kebanggaan ini, bahasa Indonesia kita pelihara dan kita kembangkan serta rasa kebanggaan pemakainya senantiasa kita bina.

Sebagai lambang identitas nasional, bahasa Indonesia kita junjung disamping bendera dan lambang negara kita. Di dalam melaksanakan fungsi ini bahasa Indonesia tentulah harus memiliki identitasnya sendiri pula sehingga ia serasi dengan lambang kebangsaan kita yang lain. Bahasa Indonesia dapat memiliki identitasnya apabila masyarakat pemakainya membina dan mengembangkannya sedemikian rupa sehingga bersih dari unsur-unsur bahasa lain.

\section{Fungsi Bahasa Indonesia}

Fungsi bahasa Indonesia dalam kedudukannya sebagai bahasa nasional yaitu sebagai alat perhubungan antarwarga, antardaerah, dan antarsuku bangsa. Berkat adanya bahasa nasional kita dapat berhubungan satu dengan yang lain sedemikian rupa sehingga kesalahpahaman sebagai akibat perbedaan latar belakang sosial budaya dan bahasa tidak perlu dikhawatirkan. Kita dapat bepergian dari pelosok yang satu ke pelosok yang lain di Tanah Air kita dengan hanya memanfaatkan bahasa Indonesia sebagai satu-satunya alat komunikasi.

Fungsi bahasa Indonesia yang keempat dalam kedudukannya sebagai bahasa nasional, adalah sebagai alat yang memungkinkan terlaksananya penyatuan berbagai suku bangsa yang memiliki latar belakang sosial budaya dan bahasa yang berbeda-beda ke dalam satu kesatuan kebangsaan yang bulat. Di dalam hubungan ini, bahasa Indonesia memungkinkan berbagai suku bangsa itu mencapai keserasian hidup sebagai bangsa yang bersatu dengan tidak perlu meninggalkan identitas kesukuan dan kesetiaan pada nilai-nilai social budaya serta latar belakang bahasa daerah yang bersangkutan. Lebih dari itu, dengan bahasa nasional itu kita dapat meletakkan kepentingan nasional jauh di atas kepentingan daerah atau golongan. 
Adapun dalam kedudukannya sebagai bahasa Negara memiliki fungsi yang pertama yaitu sebagai bahasa resmi kenegaraan, bahasa Indonesia dipakai di dalam segala upacara, peristiwa, dan kegiatan kenegaraan baik dalm bentuk lisan maupun dalam bentuk tulisan. Termasuk ke dalam kegiatan-kegiatan itu adalah penulisan dokumen-dokumen dan putusan-putusan serta surat-surat yang dikeluarkan oleh pemerintah dan badan-badan kenegaraan lainnya, serta pidatopidato kenegaraan.

Fungsi yang kedua di dalam kedudukannya sebagai bahasa negara, bahasa Indonesia merupakan bahasa pengantar di lembaga-lembaga pendidikan mulai Taman Kanak-kanak sampai dengan Perguruan Tinggi di seluruh Indonesia, kecuali di daerah-daerah, seperti daerah Aceh, Batak, Sunda, Cirebon, Jawa, Madura, Bali, dan Makasar yang menggunakan bahasa daerahnya sebagai bahasa pengantar sampai dengan tahun ketiga pendidikan dasar. Sebagai fungsi yang ketiga di dalam kedudukannya sebagai bahasa negara, bahasa Indonesia sebagai alat perhubungan pada tingkat nasional untuk kepentingan perencanaan dan pelaksanaan pembangunan nasional dan untuk kepentingan pelaksanaan pemerintah. Di dalam hubungan dengan fungsi ini, bahasa Indonesia dipakai bukan saja sebagai alat komunikasi timbale-balik antara pemerintah dan masyarakat luas, dan bukan saja sebagai alat perhubungan antardaerah dan antarsuku, melainkan juga sebagai alat perhubungan di dalam masyarakat yang sama latar belakang sosial budaya dan bahasanya.

Akhirnya, di dalam kedudukannya sebagai bahasa negara, bahasa Indonesia berfungsi sebagai alat pengembangan kebudayaan nasional, ilmu pengetahuan, dan teknologi. Di dalam hubungan ini, bahasa Indonesia adalah satu-satunya alat yang memungkinkan kita membina dan mengembangkan kebudayaan nasional sedemikian rupa sehingga ia memiliki cirri-ciri dan identitasnya sendiri, yang membedakannya dari kebudayaan daerah. Pada waktu yang sama, bahasa Indonesia kita pergunakan sebagai alat untuk 
menyatakan nilai-nilai sosial budaya nasional kita. (Halim, 1979:4-56; Moeliono, 1980: 15-31). Di luar dari apa yang dijelaskan di atas, sekarang ini fungsi bahasa Indonesia telah pula bertambah besar. Bahasa Indonesia berfungsi sebagai bahasa media massa baik yang cetak maupun yang elektronik, baik yang visual, audio, maupun audio visual harus memakai bahasa Indonesia. Media massa menjadi tumpuan kita dalam menyebarluaskan bahasa Indonesia secara baik dan benar. Sebagai sumber pemerkaya bahasa daerah, bahasa Indonesia berperan sangat penting. Beberapa kosakata bahasa Indonesia ternyata dapat memperkaya khasanah bahasa daerah, dalam hal bahasa daerah tidak memiliki kata untuk sebuah konsep.

Bahasa Indonesia dapat dipakai juga sebagai alat menyebarluaskan sastra Indonesia. Sastra Indonesia merupakan wahana pemakaian bahasa Indonesia dari segi estetis bahasa sehingga bahasa Indonesia menjadi bahasa yang penting dalam dunia internasional.

\section{Menurunnya Penutur Bahasa Indonesia}

Dengan mengetahui dua kedudukan penting sebagai bahasa nasional dan bahasa negara serta begitu banyaknya fungsi yang dimiliki bahasa Indonesia seperti itu, seharusnya bahasa Indonesia dipelajari dan dipahami dengan baik oleh generasi muda (pelajar dan mahasiswa). Kenyataanya dari hasil pengamatan dan penelitian sederhana khususnya di daerah Cirebon dan Jawa Barat pada umumnya didapatkan hasil yang cukup mengagetkan, generasi mudanya sudah mulai menganggap bahasa Indonesia itu ketinggalan zaman dan tidak merasa penting untuk dipelajari dan dipahami lebih dalam.

Melihat kenyataan seperti itu, penguasaan bahasa Indonesia pada generasi muda menjadi sangat rendah. Hal ini dapat dibuktikan dan diukur dari kemampuan mereka menggunakan bahasa Indonesia baik secara lisan maupun tulisan dalam aktivitas sehari-harinya. Hasil penilaian akademis maupun penilaian dalam Ujian Nasional-pun hasilnya belum menggembirakan. Ironisnya, justru bahasa Inggrislah yang dianggap lebih penting sehingga 
mereka sangat serius mempelajari dan menguasainya dengan baik. Tidak salah memang hal itu terjadi karena bahasa Inggris merupakan bahasa Internasional. Tetapi sebagai pengajar bahasa Indonesia, penulis merasa prihatin melihat kenyataan seperti ini. Satu hal yang harus kita sadari, belajar bahasa itu tidak hanya belajar bahasa sebagai alat komunikasi bahkan bisa lebih dari itu. Belajar bahasa itu sebenarnya sekaligus juga berarti belajar budaya. Jika demikian halnya, belajar bahasa itu erat kaitannya dengan internalisasi nilai-nilai budaya.

Sebagai contoh yang kecil, mereka lebih suka mempelajari dan menggunakan bahasa asing dibandingkan dengan bahasa kita sendiri, maka tidak menutup kemungkinan mereka juga lebih suka menginternalisasikan nilainilai budaya asing tersebut. Bisa dibayangkan dampak apa yang akan terjadi akibat dari penggunaan bahasa asing tersebut.Idealnya belajar bahasa itu harus bersifat gradasional. Artinya pembelajaran bahasa itu dilakukan sesuai dengan gradasinya, mereka diajarkan mulai dari bahasa ibu (mother language), yakni bahasa daerah, bahasa Indonesia, dan baru belajar bahasa asing (Inggris). Melalui usaha seperti ini, mereka dengan sendirinya memiliki landasan yang kuat pada bahasa daerah dan bahasa Indonesia sebelum lebih jauh melangkah belajar bahasa Inggris sebagai bahasa global. Belum selesai kita dihadapkan pada persoalan menurunnya bahasa Indonesia sebagai lingua franca sudah ditambah persoalan baru, apa itu ? Bahasa daerah pun akhir-akhir ini terutama di daerah Jawa Barat penggunaan bahasa daerahnya semakin menurun juga dan dikhawatirkan akan semakin ditinggalkan oleh masyarakat penuturnya. Hal tersebut ditandai dengan sudah semakin sedikitnya masyarakat Jawa Barat yang menggunakan bahasa daerah dalam komunikasi sehari-hari.

Kepala Dinas Pariwisata dan Kebudayaan Jawa Barat Nunung Sobari mengungkapkan, semakin berkurangnya masyarakat menggunakan bahasa daerah, kian hari kian mengkhawatirkan. " Di Jawa Barat ini setidaknya ada tiga bahasa daerah yang digunakan, yaitu bahasa Sunda, bahasa Melayu Betawi, dan bahasa Jawa Ora atau Jawa Cirebonan. Sekarang ini, penggunaan tiga 
bahasa tersebut semakin ditinggalkan masyarakat," ujar Nunung Sobari didampingi Kepala Bidang Kebudayaan, Wahyu Iskandar, Sabtu (31/1/2015) Harian Umum Pikiran Rakyat.

Dikatakan Nunung, ada sejumlah kendala ataupaun permasalahan dalam pengembangan bahasa daerah di hampir semua provinsi di Indonesia. Prioritas penggunaan bahasa asing (Inggris) dan bahasa nasional (Indonesia), dan karena hanya penggunaan bahasa daerah sebagai muatan lokal atau pelajaran tidak diutamakan, maka membuat bahasa daerah juga semakin tersisihkan. "Selama ini, bahasa Sunda, ataupun bahasa Melayu Betawi dan Jawa Cirebonan lebih difokuskan sebagai mata pelajaran bersifat muatan lokal. Padahal, karena sifatnya sebagai alat komunikasi, seharusnya bahasa daerah dijadikan sebagai bahasa pengantar dalam aktivitas pembelajaran," ujar Nunung.

Oleh karena itu, Nunung menyarankan agar ada upaya bagaimana mengajarkan bahasa daerah dengan cara yang menarik, disukai dan tidak kaku. Jangan sampai bahasa daerah ini semakin lama semakin sulit diaplikasikan oleh para siswa, untuk menumbuhkan dan merangsang minat generasi muda terhadap bahasa daerah, serta melaksanakan amanat Peraturan Daerah Nomor 14 Tahun 2014, tentang Pemeliharaan Bahasa, Sastra, dan Aksara Daerah.

Bukan hanya bahasa daerah saja yang perlu mendapat perhatian, bahasa Indonesia pun selayaknya harus sudah mendapat perhatian penuh agar tetap selalu menjadi kebanggaan bangsa Indonesia. Jati diri atau identitas suatu komunitas dapat dibentuk oleh bahasanya dalam proses interaksi antara bahasa dan konteks sosial yang berlangsung dalam evolusi. Melalui pengertian ini, bahasa adalah jati diri suatu bangsa. Jika satu bahasa lenyap atau musnah, sejalan dengan pemikiran Thornborrow (2007: 171), musnahlah khazanah ideologi, budaya dan situasi dalam bahasa itu dan sekaligus musnahlah identitas atau jati diri penutur bahasa itu.

Perlu diketahui bahawa Negara Indonesia memiliki 746 bahasa daerah (Pusat Bahasa, 2008). Jika bahasa daerah tersebut sedikit demi sedikit 
ditinggalkan oleh para penuturnya akan dapat dipastikan ikut punah jati diri dan identitas suatu daerah. Hal ini tentunya juga berdampak negatif pada perkembangan bahasa nasional kita sebagai lingua franca. Kita harus mampu mempertahankan dan mengembangkan bahasa daerah dan bahasa nasional (Indonesia) . Mau tidak mau harus ada keberanian pemerintah dan masyarakat untuk mengadakan berbagai upaya, agar bahasa yang kita miliki tetap lestari dan dicintai oleh para penuturnya. Kita memang negara yang besar serta memiliki sejarah yang panjang tentang perkembangan bahasanya, sebagaimana Penulis telah menguraikan sebelumnya.

Penulis sangat menyadari betapa kuatnya desakan arus globalisasi dan semakin meningkatnya ilmu pengetahuan dan teknologi, mau tidak mau kita juga harus mengikuti dan menyiapkan diri untuk lebih giat dalam menyikapinya, termasuk menyikapi bagaimana seharusnya bangsa Indonesia ini mempertahankan eksistensi dan jati diri bangsa melalui penggunaan bahasa Indonesia dengan baik dan benar tentunya. Tidak bosan dan pantang menyerah untuk mengajak dan menyerukan dalam setiap kesempatan agar penutur bahasa Indonesia semakin bangga dengan bahasanya. Dewasa ini sebagian orang Indonesia mengalami krisis bahasa. Karena bahasa adalah identitas maka krisis bahasa juga berarti kriris identitas. Kenyataanya menunjukkan bahwa bangsa Indonesia sedang demam atau 'gila' bahasa asing, khususnya bahasa Inggris. Hal ini semata-mata karena sebuah 'gengsi' ketakutan terhadap 'berhala' globalisasi.

Hasil pengamatan sederhana, ada anggapan masyarakat bahwa satusatunya jalan untuk selamat dari lindasan globalisasi yaitu harus menguasai bahasa Inggris. Bahkan, bahasa Inggris memiliki nilai jual yang tinggi dibanding bahasa Pribumi (Indonesia) terutama dalam tatanan wibawa sosial dan ekonomi. Berbagai merek dagang, spanduk, nama sebuah hotel, nama perusahaan, tempat-tempat penting, bahkan iklan layanan umum, kebanyakan sudah tercemar atau bercampur dengan bahasa asing, khususnya bahasa Inggris. 
Masih ingatkah kita pada sebuah kenyataan, beberapa sekolah waktu itu, khususnya di sekolah yang berada di kota-kota besar seperti Jakarta, Surabaya, dan Kota Medan menyatakan diri sebagai sekolah Internasional dengan bahasa pengantar dalam pembelajarannya menggunakan bahasa Inggris.

Penggunaan bahasa asing secara tidak proporsional, berkurangnya penutur bahasa Indonesia, serta semakin ditinggalkannya bahasa daerah, termasuk ada usaha pengambilan aset budaya kita oleh beberapa negara tetangga menjadi fakta bahwa bangsa ini sedang mengalami krisis jati diri sebagai suatu bangsa. Hal ini bisa jadi karena ketidaktahuan kita terhadap kedudukan dan fungsi bahasa dalam kehidupan berbangsa dan bernegara, serta kualitas hidup yang rendah.

\section{Kesimpulan}

Pemerintah sebenarnya sudah melakukan berbagai upaya serius agar pemakaian bahasa Indonesia secara baik dan benar disetiap kegiatan sehari-hari terus digalakan, ini wujud komitmen pemerintah yang menegaskan bahwa bahasa Indonesia memiliki kedudukan sebagai bahasa nasional dan sebagai bahasa negara. Tentu upaya pemerintah ini harus kita dukung bersama, apalah artinya sebuah usaha kalau tidak didukung oleh seluruh bangsa Indonesia ini. Karena Penulis adalah seorang pendidik yang mengajarkan materi Bahasa Indonesia, maka mari kita wujudkan Pendidikan dan Pengajaran Bahasa Indonesia yang baik dan benar, supaya tidak ditinggalkan oleh para penuturnya. Para pelajar dan mahasiswa harus kita bekali dengan pengetahuan dan keterampilan berbahasa Indonesia secara berkualitas sebagai lingua franca, bahasa perantara dalam pergaulan berbangsa dan bernegara.

Sudah barang tentu tulisan yang sependapat ini sudah berulang kali kita baca di berbagai media, maka perlu mendapat apresiasi agar para penulis yang memiliki ide atau gagasan serupa untuk tidak bosan menyuarakan isi hatinya demi tegak dan jayanya bahasa kita. Besar harapan, semakin banyak yang menulis 
dan membaca tentu akan semakin banyak yang memperhatikan, dan kalau makin banyak yang memperhatikan tentu makin banyak yang mengerti dan memahami. Perlahan namum pasti, karena semakin banyak yang memahami maka akan timbul niatan untuk semakin mencintai dan memiliki kebanggaan tersendiri. Bangga terhadap bahasa dan budayanya sendiri.

\section{Daftar Pustaka}

Alwi, Hasan, Soejono Dardjowidjojo, Hans Lapoliwa, Anton M. Moeliono. 1998. Tata Bahasa Baku Bahasa Indonesia. Edisi Ketiga. Jakarta: Balai Pustaka.

Arifin, E. Zaenal dan S. Amran Tasai. 2010. Cermat Berbahasa Indonesia. Jakarta : Akademika Pressindo.

Badudu, J.S. 1975. Pelik-Pelik Bahasa Indonesia. Cetakan IX. Bandung : Pustaka Prima.

Depdiknas. 2006. “Acuan Pembelajaran Mata Kuliah Pengembangan Kepribadian Bahasa Indonesia.” Yogyakarta : Seminar Nasional Dosen Bahasa Indonesia.

Halim, Amran. (Editor). 1976. Politik Bahasa Nasional 2. Jakarta : Pusat Pembinaan dan Pengembangan Bahasa.

Keraf, Gorys. 1980. Komposisi. Ende-Flores : Nusa Indah. 